\title{
Análise Setorial e Topografia da Estrutura Produtiva: As Cooperativas Agropecuárias no Paraná
}

\author{
- Rossana lott Rodrigues* JOAQuim José Martins Guilhoto **
}

\begin{abstract}
RESUMO
O objetivo deste artigo é analisar a estrutura produtiva da economia paranaense enfatizando o papel das cooperativas agropecuárias no desenvolvimento do Estado nos anos de 1980, 1985, 1990 e 1995. A partir de tabelas de insumo-produto estimadas para o Paraná foi possível constatar que: i) nos anos de 1980 e 1985 o setor Cooperativa foi chave na economia estadual; ii) as cooperativas agropecuárias apresentaram, para todos os anos estudados, coeficientes técnicos de produção bastante similares aos das empresas não-cooperativas, mostrando que aquelas estão incorporando em seus processos produtivos o progresso tecnológico consolidado pelas não-cooperativas; iii) alguns setores da indústria de transformação, tais como Máquinas e Equipamentos, Material de Transporte e, em menor grau, Metalurgia e Material Elétrico/Eletrônico parecem emergir na economia paranaense; iv) a economia paranaense revelou maior diversificação da estrutura produtiva, crescimento das relações externas e, conseqüentemente, incremento da complexidade econômica.
\end{abstract}

\section{Palavras-CHAVE}

insumo-produto, análise setorial, estrutura produtiva, cooperativas agropecuárias

\begin{abstract}
The goal of this paper is to analyze the productive structure of the Parana economy emphasizing the role of the agricultural cooperatives in the state development for the years 1980, 1985, 1990 and 1995. Using input-output tables estimated for those years it was possible to detect that: i) for the years 1980 and 1985 the Cooperative sector was a key sector for the Parana economy; ii) in all years analyzed, the agricultural cooperatives presented technical coefficients of production very similar to those of the non-cooperative sector, showing that the cooperatives are incorporating in their productive process the technological progress that have been consolidated by the non-cooperative sector; iii) some sectors of the transformation industry, like Machinery and Equipment, Transport Equipment and, in a lesser scale, Metal Products and Electrical/Electronic Equipment seem to be increasing their participation in the state economy; iv) the Parana economy showed more diversification in the productive structure, more openness to external relations and, consequently, more economic complexity.
\end{abstract}

\section{KEY WORDS}

input-output, sectoral analysis, productive structure, agricultural cooperatives

\author{
JEL CLASSIFICATION \\ D57, RII
}

\footnotetext{
* Professor Associado do Departamento de Economia da Universidade Estadual de Londrina - UEL. End. para contato: Universidade Estadual de Londrina - CESA - Departamento de Economia - Campus Universitário - Rodovia Celso Garcia Cid, Km 380 - CEP: 8605 I-990 - Londrina, Paraná. E-mail: rlott@uel.br e rlott@sercomtel.com.br.

* Professor Titular da FEA/USP, do Regional Economics Applications Laboratory (REAL), University of Illinois, e pesquisador do CNPq. E-mail: guilhoto@usp.br. End. para contato: FEA-USP - Av. Prof. Luciano Gualberto 908 - CEP: 05508-0I0 - Cidade Universitária - São Paulo - SP.

(Recebido em maio de 2005. Aceito para publicação em setembro de 2006).
} 


\section{INTRODUÇÃO}

No Brasil, as cooperativas agropecuárias representavam, em 1997, 30\% de todo o setor cooperativista nacional. Nesse ano, existiam 1.410 cooperativas agropecuárias, reunindo 923.625 cooperados, gerando 112.835 empregos diretos e vinculando 5.182.300 pessoas cujas atividades estão, de alguma forma, a elas ligadas. (OCB, 1997).

No âmbito regional, o Sul se destaca no segmento agropecuário pelo número de associados e funcionários envolvidos nas cooperativas. São 313 cooperativas, com 468.277 associados e 65.219 funcionários, 50,7 e 57,8\% do total do segmento, respectivamente. (OCB, 1997).

Na região Sul, o Estado do Paraná é o que apresenta o cooperativismo mais organizado, e nele o segmento agropecuário é o mais desenvolvido. Em 1996, eram 66 cooperativas e 119.756 associados, dos quais $75 \%$ trabalhavam em módulos de área de até 50 ha. (OCEPAR, 1997).

As cooperativas paranaenses, notadamente as do ramo agropecuário, têm sido beneficiadas com diversos estudos, tanto realizados por órgãos estaduais, tais como Organização e Sindicato das Cooperativas do Paraná (OCEPAR), Instituto Paranaense de Desenvolvimento Econômico e Social (IPARDES), Empresa de Assistência Técnica e Extensão Rural/PR (EMATER/PR), quanto por pesquisadores ligados a universidades e órgãos públicos de pesquisa.

Os estudos mais profundos têm-se dedicado a realizar levantamento histórico do cooperativismo e a verificar as causas da crise enfrentada pelo setor, notadamente nos anos 1980. No aspecto microeconômico, a preocupação está centrada em avaliar a eficiência empresarial das cooperativas, analisar socioeconomicamente as empresas por meio de inter-relações e realizar estudos de casos que buscam levantar problemas e apontar soluçóes específicas para cooperativas que apresentam dificuldades quanto ao relacionamento cooperativa/cooperado, às decisões de investimento e, mais recentemente, quanto à capitalização e abertura de capital.

Todos esses trabalhos têm o mérito de contribuir para maior conhecimento do sistema cooperativista em geral, e das cooperativas paranaenses, notadamente as agropecuárias. Entretanto, até o momento não foram constatados, na literatura, estudos que tenham por objetivo identificar a importância do 'setor cooperativa'l relativamente aos demais setores da economia paranaense, buscando verificar as ligaçôes interse-

1 As cooperativas agropecuárias são analisadas, no presente estudo, formando um setor dentro da economia paranaense, de acordo com as atividades que desenvolvem. 
toriais estabelecidas, conhecer melhor as potencialidades desse setor no que se refere à sua capacidade de gerar e disseminar crescimento e, a partir daí, colaborar com as cooperativas no direcionamento dos investimentos, e com os órgãos públicos, na implementação de políticas econômicas ou de projetos de desenvolvimento.

Assim, o objetivo geral deste trabalho é analisar a estrutura produtiva da economia paranaense, com destaque para o papel das cooperativas agropecuárias no desenvolvimento do Estado nos anos de 1980, 1985, 1990 e 1995.

Além desta introdução, na seção l é apresentada a metodologia utilizada no estudo, incluindo os dados e os métodos de análise. Na seção 2 são analisados os resultados e, por fim, são apresentadas as consideraçôes finais.

\section{METODOLOGLA}

\subsection{Dimensionamento das Cooperativas Agropecuárias na Economia do Paraná}

Para atender ao objetivo proposto empregou-se a análise de insumo-produto, pois é o instrumental analítico mais adequado para identificar, de forma sistêmica, a interdependência setorial, bem como as políticas econômicas que podem ser implementadas no sentido de permitir maior participação das cooperativas agropecuárias na economia estadual.

A pesquisa foi desenvolvida para os anos de 1980, 1985, 1990 e 1995, utilizando-se de uma série temporal de matrizes estimadas por Rodrigues (2000), estruturadas em 33 setores, dentre eles o específico para as cooperativas agropecuárias, como pode ser visto na tabela e figuras apresentadas adiante.

\subsection{As Ligaçôes Industriais e os Setores-chave}

A análise das relações intersetoriais de dada economia está fundamentada no fato de que os produtos podem ser usados tanto pelas indústrias (produtos intermediários) quanto pelos consumidores para atender às necessidades da demanda final. Considerando que no modelo de insumo-produto a demanda final é autônoma, torna-se possível determinar a quantidade a ser produzida em cada setor e a intensidade relativa dos efeitos nas diferentes indústrias, ou seja, as ligações intersetoriais.

Desse modo, uma das formas de verificar a participação das cooperativas agropecuárias na economia estadual é calcular os índices de ligações, os quais permitem 
detectar o poder de encadeamento e a importância das cooperativas agropecuárias relativamente aos outros setores na economia paranaense.

Na literatura estão registrados vários métodos que objetivam medir as ligações intersetoriais com o intuito de identificar setores-chave, na definição de Rasmussen (1956) e Hirschman (1958), ou pólos de crescimento, na visão de Perroux (1977) e Myrdal (1957). Recentemente, o conceito de 'ligações' tem atraído considerável interesse como meio de identificar setores-chave para a promoção de estratégias de desenvolvimento industrial. Acredita-se que a concentração de recursos, especialmente capital e habilidade empresarial, em setores-chave ocasionará um crescimento mais rápido do produto e do emprego do que se fossem alocados em outros setores. (McGilvray, 1977).

Embora exista consenso no que se refere à importância das ligações intersetoriais na determinação de estímulos ao crescimento econômico e no tocante ao fato de que o processo de transformação econômica é freqüentemente estimulado por número relativamente pequeno de setores, parece haver pouco acordo com relação à identificação de setores-chave. Para McGilvray (1977), fatores que desempenham papel dominante no processo de desenvolvimento dos países, como padrốes de comércio e competitividade internacionais, disponibilidade de recursos naturais, habilidade/talento empresarial e tecnologia, não são explicitamente reconhecidos quando se busca a determinação de setores-chave. Segundo Guilhoto et al. (1994), parte da confusão deve-se à dificuldade de se identificar quais seriam os setores que contribuem acima da média para a economia, tanto numa perspectiva $e x$-post quanto $e x$-ante.

Considerando os índices de ligações que podem ser derivados das tabelas de insumoproduto como um primeiro passo na identificação de áreas potenciais de projetos de desenvolvimento (McGilvray, 1977), são expostos, nesta seção, os métodos usados para identificar os setores que mais dinamizaram a economia paranaense nos anos estudados, dada a sua estrutura produtiva modificada pela consideração explícita das cooperativas agropecuárias.

\subsubsection{Os Índices de Rasmussen-Hirschman}

Os índices de ligações de Rasmussen-Hirschman têm sido muito aplicados e comentados na literatura por McGilvray (1977), Hewings (1982), Guilhoto et al. (1994), dentre outros. Essas medidas, inicialmente idealizadas por Rasmussen (1956), foram usadas como meio de identificar setores-chave por Hirschman (1958).

Considerando a estrutura interna da economia baseada no modelo de insumo-produto e seguindo os dois últimos autores, pode-se determinar os setores que teriam o maior poder de encadeamento dentro da economia, isto é, pode-se calcular os índices 
de ligações para trás, que estimam o quanto um setor demanda dos outros setores, e os índices de ligações para frente, que informam o quanto um setor é demandado pelos demais.

Desse modo, com base na equação $L=(I-A)^{-1}$, em que I é a matriz identidade e A é a matriz de coeficientes técnicos de insumos diretos, define-se $l_{i j}$ como um elemento da matriz inversa de Leontief, $L, L^{*}$ como a média de todos os elementos de $L$ e $L_{\bullet} j$ e $L_{i \bullet}$ como a soma dos elementos de uma coluna e de uma linha típica de $L$, dada, respectivamente, como:

$$
L_{\bullet j}=\sum_{i=1}^{n} l_{i j} \quad \text { e } \quad L_{i \bullet}=\sum_{j=1}^{n} l_{i j} \quad \mathrm{i}, \mathrm{j}=1,2, \ldots \mathrm{n}
$$

Assim:

Índices de ligações para trás:

$$
U_{j}=\left[L_{\bullet j} / n\right] / L^{*}
$$

Índices de ligações para frente:

$$
U_{i}=\left[L_{i \bullet} / n\right] / L^{*}
$$

Para Rasmussen e Hirschman, valores maiores do que 1, tanto dos índices de ligações para trás quanto para frente, indicam setores acima da média e, portanto, setoreschave para o crescimento da economia.

\subsection{As Relações Cumulativas Setoriais}

As ligações diretas entre setores podem ser vistas como canais através dos quais passam os impulsos econômicos. Em que pese a importância destas informações para os formuladores de política econômica, Oosterhaven et al. (1999a e 1999b) apontam duas limitações relativas a essas ligações: a) o tamanho dessas ligações não informa sobre a proporção dos impulsos transmitidos; b) a presença de uma ligação não informa a direção do possível impulso.

Ademais, uma das críticas feitas aos índices de Rasmussen-Hirschman para frente é de que eles deveriam ser calculados usando-se o coeficiente de produto (1.5) e não o coeficiente de insumo, dado por $\left(a_{i j}=Z_{i j} / X_{j}\right)$. A razão está no fato de que os índices de ligação para frente mostram o quanto um setor é demandado pelos, ou fornece para 
os, outros setores. Neste caso, o que está sendo demandado ou ofertado é produto final do setor em questão, apesar de ser usado como insumo pelos outros setores.

Dentro da proposta deste estudo buscou-se superar essas limitações utilizando a metodologia proposta pelos autores acima, que esboça os dois extremos entre os quais, mais provavelmente, os verdadeiros efeitos podem ser encontrados.

Um dos extremos é o tradicional modelo da demanda induzida com seu modelo dual de preço cost-push. O outro extremo é o modelo de oferta induzida com seu modelo de preço demand-pull.

A versão tradicional do modelo de demanda induzida tem sua solução representada por:

$$
X=(I-A)^{-1} Y
$$

em que $(I-A)^{-1}$ é a matriz de coeficientes técnicos de insumo diretos e indiretos, ou matriz inversa de Leontief, como mencionado anteriormente. Fazendo $L(\mathrm{n} \times \mathrm{n})=$ $(I-A)^{-1}$, cada elemento $l_{i j}$ da matriz inversa de Leontief mostra os requisitos diretos e indiretos da produção total do setor $i$ necessários para produzir uma unidade de demanda final do setor $j$.

A equação (1.4) fornece a solução do modelo de Leontief. Assumindo que $(L-I)$ indica o total das ligações diretas e indiretas entre setores, são definidas as ligaçôes cumulativas para trás por setor. Esta medida tem as características do modelo de Leontief, quais sejam: a demanda é perfeitamente preço-inelástica, a oferta é perfeitamente preço-elástica, os setores produzem bens homogêneos e todos os insumos são usados em proporçóes fixas pelos setores.

Por outro lado, o modelo de oferta induzida assume que a oferta primária de insumos por setor ( $\left.V^{\prime}\right)$ é exógena. Toda mudança nessa oferta desencadeia alteraçóes no insumo total por setor $\left(\mathrm{X}^{\prime}\right)$ via coeficiente de produto dado por:

$$
b_{i j}=\left(Z_{i j} / X_{i}\right)
$$

O conjunto dos coeficientes $\left(b_{i j}\right)$ forma a matriz $\mathrm{B}$, matriz de coeficientes de produto. A oferta intermediária de produtos por setor é, então, determinada por (X'B). Mudanças nessa oferta, por sua vez, promovem mudanças no insumo total, e assim por diante, terminando na solução do modelo de Ghosh dada por: 


$$
X^{\prime}=V^{\prime}\left(I+B+B^{2}+B^{3}+\ldots\right)=V^{\prime}(I-B)^{-1}=V^{\prime} G
$$

em que Gé a matriz inversa de Ghosh.

A interpretação padrão desse modelo pelo lado da quantidade não é aceitável, visto que isto implicaria acreditar que a oferta é perfeitamente preço-inelástica, a demanda é perfeitamente preço-elástica, os insumos são perfeitamente substituíveis entre os setores e o produto é produzido em proporções fixas. Diante disso, a interpretação em termos de efeito preço é a mais indicada. Assim, o modelo descreve as mudanças no valor do produto quando as alterações nos preços dos insumos primários são inteira e proporcionalmente repassadas ao cliente. (Oosterhaven et al., 1999a e 1999b).

Desse modo, somente como um artifício descritivo $(G-I)$ pode ser usada para indicar o total de ligações diretas e indiretas entre setores, ou seja, as ligações cumulativas para frente por setor.

\subsection{Matriz de Intensidade}

Recentemente, Sonis et al. (1997) e Sonis e Hewings (1999) expandiram a técnica do campo de influência para introduzir a noção de intensidade, a qual pode ser visualizada por meio de matriz tridimensional. Nessa abordagem, deriva-se a matriz do produto dos multiplicadores (MPM), que revela a hierarquia das ligaçóes para trás e para frente, delineando a 'topografia econômica' a ela relacionada e refletindo a estrutura de cruz associada à MPM.

Mais especificamente, a MPM pode ser derivada a partir dos multiplicadores das linhas e das colunas da matriz inversa de Leontief (ver seção 1.2.1). Assim, os vetores linha e coluna dos multiplicadores coluna e linha podem ser apresentados, respectivamente, como:

$$
M_{c}(L)=\left[\begin{array}{llll}
L_{\bullet 1} & L_{\bullet 2} & \ldots & L_{\bullet}
\end{array}\right] \text { e } M_{l}(L)=\left(\begin{array}{c}
L_{1 \bullet} \\
L_{2} \\
\ldots \\
L_{n \bullet}
\end{array}\right)
$$

Admitindo que $l_{\text {.. }}$ seja a soma de todos os elementos da matriz inversa de Leontief, denominada de intensidade global da matriz, dada por: 


$$
l_{. .}=\sum_{i=1}^{n} \sum_{j=1}^{n} l_{i j}
$$

define-se a matriz de intensidade ou a MPM como:

$$
M=\frac{1}{l_{\bullet \bullet}}\left\|L_{i \bullet} L_{\bullet j}\right\|=\frac{1}{l_{\bullet \bullet}}\left(\begin{array}{c}
L_{\bullet \bullet} \\
L_{2} \\
\ldots \\
L_{n \bullet}
\end{array}\right)\left(\begin{array}{llll}
L_{\bullet 1} & L_{\bullet 2} & \ldots & L_{\bullet n}
\end{array}\right)=\left\|m_{i j}\right\|
$$

Ainda de acordo com os autores citados, a estrutura da MPM pode ser melhor entendida do seguinte modo: considere os maiores multiplicadores coluna e linha da inversa de Leontief, $L_{\bullet j}$ e $L_{i \bullet}$, e o elemento $m_{i 0 j 0}=\frac{1}{l_{\bullet \bullet}} L_{i 0 \bullet} L_{\bullet j 0}$, localizado na célula $\left(i_{0}, j_{0}\right)$ da MPM. Admitindo que todas as suas linhas são proporcionais à $i_{0}^{\text {th }}$ linha, que os elementos desta linha são maiores que os elementos correspondentes de todas as outras linhas e que a mesma propriedade é aplicada à $j_{0}^{\text {th }}$ coluna de MPM, tem-se que o elemento localizado na célula $\left(i_{0}, j_{0}\right)$ define o centro do maior cruzamento dentro da MPM. Se este cruzamento é excluído de MPM, o segundo maior cruzamento pode ser identificado, e assim por diante.

A organização das linhas e colunas da MPM pode ser feita de modo que os centros dos cruzamentos correspondentes apareçam na diagonal principal. Neste caso, a MPM mostrará 'topografia econômica' descendente, baseada na sequiência de ordenação, por tamanho, dos multiplicadores coluna e linha.

Este arranjo também revela a hierarquia descendente dos índices para frente e para trás de Rasmussen-Hirschman. (Sonis et al., 1997 e Sonis e Hewings, 1999). Observando a parte da topografia com índices de Rasmussen-Hirschman maiores do que 1 , será possível identificar os setores-chave na economia. Contudo, a construção da MPM é importante, pois permite explorar, de forma consistente e complementar, a estrutura destes índices tradicionais.

A matriz MPM pode ser construída para diferentes regiões ou para a mesma região em diferentes pontos no tempo, que é o caso do presente estudo, criando a possibilidade 
de estabelecer a classificação sistemática das várias regiões ou dos diversos momentos da economia.

Desse modo, adotando como numeraire ou base a ordenação por tamanho dos multiplicadores coluna e linha de certa economia ou de dado período, a topografia econômica pode ser visualmente comparada: desvios da topografia descendente retratada pela economia tomada como base refletirão diferenças na estrutura econômica entre as regiões ou entre períodos distintos em uma mesma região. Estas diferenças mostrarão, no caso de estudos com mais de uma região, variação no conjunto de indústrias das regiôes, variação no grau da intermediação intra-regional e variação na tecnologia. Considerando uma região em pontos diferentes no tempo, que é o caso desse estudo, as alterações poderão refletir variação no mix de indústrias, variações no grau de ligações setoriais, bem como mudanças na tecnologia ocorridas nesta economia.

A topografia econômica resultante da MPM, embora não substitua outras técnicas, constitui ferramenta complementar na definição preliminar de diferenças e similaridades entre economias ou entre diferentes períodos da mesma economia.

\section{RESULTADOS E DISCUSSÃO}

\subsection{Ligaçôes Industriais e Setores-chave na Economia do Paraná}

\subsubsection{Os Índices de Rasmussen-Hirschman}

A Tabela 1 mostra os resultados dos índices de ligações de Rasmussen-Hirschman para os anos e setores estudados, bem como a ordem de importância dos mesmos na economia.

Uma visão panorâmica da Tabela 1 permite destacar, para os quatro anos analisados, somente 2 setores-chave para o crescimento da economia paranaense, levando em conta o conceito restrito, ou seja, aquele que apresenta, simultaneamente, índices de ligações para frente e para trás maiores que 1: Celulose, Papel e Gráfica (10) e Indústria Têxtil (15), ambos componentes da indústria de transformação.

Levando em conta somente os anos de 1980 e 1985, além dos dois setores acima mencionados, o setor Cooperativa (1) e o setor Serviços Industriais de Utilidade Pública (25), este último em 1985, também foram chave na economia estadual (Tabela 1). Entretanto, a evolução do perfil da estrutura produtiva paranaense pode ser melhor caracterizada considerando a definição menos restrita de setores-chave, segundo a 
qual índices para frente ou para trás maiores que 1 indicam setores dinâmicos e, portanto, importantes para o crescimento da economia. Dentro dessa perspectiva, o Paraná apresentou, além dos setores assinalados anteriormente, 17 setores-chave em 1980 (11 com ligações para trás e 6 com ligações para frente), 17 em 1985 (12 com ligações para trás e 5 com ligações para frente), 19 em 1990 (11 com ligações para trás e 8 com ligações para frente) e 19 em 1995 (12 com ligações para trás e 7 com ligações para frente).

Essas informações evidenciaram as seguintes características da economia paranaense nesses anos: a) a conjugação de índices de ligações para trás elevados em todos os setores alimentares (17 a 23) com índices de ligações para frente mais elevados nos setores Agropecuária não-Cooperativa (2), Química (12) e Serviços (25, 27, 28 e 33) permitiu afirmar que o Paraná detinha, ainda, parque industrial pouco diversificado, centrado nas indústrias produtoras de alimentos e na agropecuária e química enquanto fornecedoras de matérias-primas; b) o número de setores com ligações para trás foi praticamente o dobro do número de setores com ligações para frente, evidenciando que são aceitáveis políticas que objetivem estimular a demanda por insumos intermediários, notadamente se essa demanda for atendida por insumos domésticos; c) o comportamento dos índices de ligações para trás dos setores alimentares apontou na direção de queda da importância dos mais tradicionais, como Indústria do Café (17), enquanto setores indutores do crescimento da economia estadual; d) por outro lado, os setores alimentares mais modernos ou com novas atividades registraram menor decréscimo, a exemplo de Abate de Animais (19), Indústria de Laticínios (20) e Fabricação de Outros Produtos Alimentares (23), ou mesmo crescimento no seu dinamismo, como foi o caso de Fabricação de Óleos Vegetais (22); e) outros setores da indústria de transformação, tais como Máquinas e Equipamentos (6), Material de Transporte (8) e, em menor grau, Metalurgia (5) e Material Elétrico/Eletrônico (7) parecem emergir na economia paranaense, delineando tendência futura de maior diversificação industrial; f) os setores do ramo serviços ganharam importância para o crescimento da economia estadual. 
TABELA 1 - ÍNDICES DE LIGAÇÕES DE RASMUSSEN-HIRSCHMAN, PARANÁ, 1980, 1985, 1990 E 1995

\begin{tabular}{|c|c|c|c|c|c|c|c|c|}
\hline \multirow{2}{*}{ Setores } & \multicolumn{4}{|c|}{1980} & \multicolumn{4}{|c|}{1985} \\
\hline & Trás & Ordem & Frente & Ordem & Trás & Ordem & Frente & Ordem \\
\hline${ }^{1}$ Cooperativa & 1,063 & 12 & 1,535 & 4 & 1,067 & 12 & 1,813 & 3 \\
\hline 2 Agropecuária não-Cooperativa & 0,924 & 19 & 2,750 & 2 & 0,923 & 20 & 2,522 & 2 \\
\hline 3 Extrativa Mineral & 0,827 & 27 & 0,619 & 30 & 0,774 & 30 & 0,679 & 25 \\
\hline${ }^{4}$ Fabricação de Minerais não Metálicos & 1,002 & 14 & 0,897 & 11 & 1,060 & 13 & 0,946 & 10 \\
\hline${ }^{5}$ Metalurgia & 0,827 & 26 & 0,774 & 17 & 0,810 & 28 & 0,741 & 19 \\
\hline 6 Máquinas e Equipamentos & 0,813 & 29 & 0,794 & 16 & 0,786 & 29 & 0,807 & 14 \\
\hline${ }^{7}$ Material Elétrico/Eletrônico & 0,833 & 23 & 0,655 & 23 & 0,836 & 26 & 0,714 & 23 \\
\hline${ }^{8}$ Material de Transporte & 0,817 & 28 & 0,636 & 27 & 0,837 & 25 & 0,722 & 22 \\
\hline${ }^{9}$ Madeira e Mobiliário & 1,121 & 8 & 0,848 & 12 & 1,069 & 11 & 0,801 & 15 \\
\hline 10 Celulose, Papel e Gráfica & 1,134 & 7 & 1,178 & 7 & 1,111 & 9 & 1,207 & 8 \\
\hline 11 Indústria da Borracha & 0,990 & 16 & 0,657 & 22 & 0,912 & 21 & 0,644 & 30 \\
\hline 12 Química & 0,887 & 21 & 2,992 & 1 & 0,938 & 18 & 3,348 & 1 \\
\hline${ }^{13}$ Farmacêutica e Veterinária & 0,998 & 15 & 0,587 & 33 & 1,015 & 16 & 0,599 & 33 \\
\hline 14 Indústria de Artigos de Plásticos & 1,066 & 10 & 0,720 & 21 & 1,092 & 10 & 0,726 & 21 \\
\hline 15 Indústria Têxtil & 1,118 & 9 & 1,103 & 8 & 1,157 & 7 & 1,203 & 9 \\
\hline 16 Vestuário, Calçados, Couros e Peles & 1,019 & 13 & 0,593 & 31 & 1,033 & 14 & 0,612 & 31 \\
\hline 17 Indústria do Café não-Cooperativa & 1,644 & 1 & 0,830 & 14 & 1,466 & 1 & 0,730 & 20 \\
\hline${ }^{18}$ Beneficiamento de Prod. Vegetais não-Cooperativa & 1,213 & 6 & 0,725 & 20 & 1,120 & 8 & 0,745 & 18 \\
\hline${ }^{19}$ Abate de Animais não-Cooperativa & 1,349 & 3 & 0,630 & 28 & 1,387 & 3 & 0,678 & 26 \\
\hline 20 Indústria de Laticínios não-Cooperativa & 1,334 & 4 & 0,592 & 32 & 1,247 & 5 & 0,603 & 32 \\
\hline${ }^{21}$ Fabricação de Açúcar não-Cooperativa & 1,064 & 11 & 0,768 & 18 & 1,210 & 6 & 0,810 & 13 \\
\hline 22 Fabricação de Óleos Vegetais não-Cooperativa & 1,373 & 2 & 0,812 & 15 & 1,399 & 2 & 0,855 & 11 \\
\hline${ }^{23}$ Fab. de Outros Prod. Alimentares não-Cooperativa & 1,219 & 5 & 0,920 & 10 & 1,278 & 4 & 0,773 & 16 \\
\hline 24 Indústrias Diversas & 0,853 & 22 & 0,646 & 26 & 0,888 & 22 & 0,656 & 27 \\
\hline 25 Serviços Industriais de Utilidade Pública & 0,914 & 20 & 1,021 & 9 & 1,026 & 15 & 1,224 & 7 \\
\hline${ }^{26}$ Construção Civil & 0,960 & 18 & 0,753 & 19 & 0,939 & 17 & 0,753 & 17 \\
\hline 27 Comércio & 0,832 & 24 & 1,306 & 5 & 0,843 & 24 & 1,632 & 4 \\
\hline 28 Transportes & 0,831 & 25 & 1,203 & 6 & 0,923 & 19 & 1,361 & 5 \\
\hline 29 Comunicações & 0,759 & 31 & 0,646 & 25 & 0,731 & 31 & 0,685 & 24 \\
\hline 30 Instituições Financeiras & 0,730 & 32 & 0,832 & 13 & 0,702 & 33 & 0,821 & 12 \\
\hline${ }^{31}$ Aluguel de Imóveis & 0,709 & 33 & 0,649 & 24 & 0,710 & 32 & 0,653 & 28 \\
\hline 32 Administração Pública & 0,802 & 30 & 0,626 & 29 & 0,835 & 27 & 0,649 & 29 \\
\hline 33 Outros Serviços & 0,973 & 17 & 2,706 & 3 & 0,878 & 23 & 1,287 & 6 \\
\hline
\end{tabular}

(continua) 
(continuação)

\begin{tabular}{|c|c|c|c|c|c|c|c|c|}
\hline \multirow{2}{*}{ Setores } & \multicolumn{4}{|c|}{1990} & \multicolumn{4}{|c|}{1995} \\
\hline & Trás & Ordem & Frente & Ordem & Trás & Ordem & Frente & Ordem \\
\hline 1 Cooperativa & 0,980 & 15 & 1,729 & 3 & 0,994 & 15 & 1,820 & 3 \\
\hline 2 Agropecuária não-Cooperativa & 0,886 & 26 & 2,231 & 2 & 0,907 & 22 & 2,418 & 1 \\
\hline 3 Extrativa Mineral & 0,915 & 22 & 0,790 & 19 & 0,943 & 21 & 0,733 & 26 \\
\hline 4 Fabricação de Minerais não Metálicos & 1,074 & 13 & 0,985 & 12 & 1,061 & 9 & 0,963 & 11 \\
\hline 5 Metalurgia & 0,906 & 24 & 0,902 & 13 & 0,891 & 24 & 0,853 & 15 \\
\hline 6 Máquinas e Equipamentos & 0,907 & 23 & 1,113 & 10 & 0,828 & 30 & 0,931 & 13 \\
\hline 7 Material Elétrico/Eletrônico & 0,977 & 16 & 0,879 & 14 & 0,950 & 19 & 0,835 & 16 \\
\hline 8 Material de Transporte & 1,097 & 10 & 0,996 & 11 & 1,030 & 12 & 0,960 & 12 \\
\hline 9 Madeira e Mobiliário & 1,112 & 9 & 0,818 & 16 & 1,107 & 8 & 0,828 & 18 \\
\hline 10 Celulose, Papel e Gráfica & 1,224 & 4 & 1,307 & 8 & 1,210 & 5 & 1,266 & 7 \\
\hline 11 Indústria da Borracha & 0,903 & 25 & 0,649 & 30 & 0,881 & 25 & 0,649 & 31 \\
\hline 12 Química & 0,951 & 18 & 2,379 & 1 & 0,944 & 20 & 2,056 & 2 \\
\hline 13 Farmacêutica e Veterinária & 0,995 & 14 & 0,591 & 32 & 0,988 & 16 & 0,641 & 32 \\
\hline 14 Indústria de Artigos de Plásticos & 0,966 & 17 & 0,856 & 15 & 0,974 & 17 & 0,809 & 19 \\
\hline 15 Indústria Têxtil & 1,091 & 11 & 1,177 & 9 & 1,058 & 10 & 1,042 & 9 \\
\hline 16 Vestuário, Calçados, Couros e Peles & 1,080 & 12 & 0,652 & 29 & 1,036 & 11 & 0,682 & 29 \\
\hline 17 Indústria do Café não-Cooperativa & 1,324 & 2 & 0,668 & 27 & 1,027 & 13 & 0,681 & 30 \\
\hline 18 Beneficiamento de Prod. Vegetais não-Cooperativa & 1,197 & 6 & 0,725 & 23 & 1,202 & 7 & 0,744 & 24 \\
\hline 19 Abate de Animais não-Cooperativa & 1,306 & 3 & 0,646 & 31 & 1,338 & 2 & 0,703 & 27 \\
\hline 20 Indústria de Laticínios não-Cooperativa & 1,169 & 7 & 0,590 & 33 & 1,211 & 3 & 0,636 & 33 \\
\hline 21 Fabricação de Açúcar não-Cooperativa & 1,133 & 8 & 0,697 & 26 & 1,210 & 4 & 0,696 & 28 \\
\hline 22 Fabricação de Óleos Vegetais não-Cooperativa & 1,381 & 1 & 0,815 & 17 & 1,414 & 1 & 0,853 & 14 \\
\hline 23 Fab. de Outros Prod. Alimentares não-Cooperativa & 1,219 & 5 & 0,733 & 20 & 1,202 & 6 & 0,829 & 17 \\
\hline 24 Indústrias Diversas & 0,951 & 19 & 0,797 & 18 & 1,009 & 14 & 0,760 & 22 \\
\hline 25 Serviços Industriais de Utilidade Pública & 0,945 & 20 & 1,336 & 6 & 0,954 & 18 & 1,358 & 5 \\
\hline 26 Construção Civil & 0,930 & 21 & 0,730 & 22 & 0,878 & 26 & 0,748 & 23 \\
\hline 27 Comércio & 0,827 & 29 & 1,700 & 4 & 0,876 & 27 & 1,626 & 4 \\
\hline 28 Transportes & 0,876 & 27 & 1,368 & 5 & 0,907 & 23 & 1,322 & 6 \\
\hline 29 Comunicações & 0,719 & 31 & 0,719 & 24 & 0,743 & 32 & 0,778 & 21 \\
\hline 30 Instituições Financeiras & 0,666 & 32 & 0,718 & 25 & 0,817 & 31 & 0,989 & 10 \\
\hline 31 Aluguel de Imóveis & 0,664 & 33 & 0,654 & 28 & 0,673 & 33 & 0,737 & 25 \\
\hline 32 Administração Pública & 0,774 & 30 & 0,731 & 21 & 0,868 & 29 & 0,799 & 20 \\
\hline 33 Outros Serviços & 0,856 & 28 & 1,323 & 7 & 0,871 & 28 & 1,257 & 8 \\
\hline
\end{tabular}

Fonte: dados estimados pelos autores.

Uma incursão pela história econômica paranaense permite constatar que os resultados apontados acima são fruto de uma conjugação de fatores que possibilitaram a econo- 
mia do Estado atravessar a fase privilegiada de guinada em sua estrutura produtiva nos anos 1990. O trabalho de Lourenço (2000) faz esse retrospecto.

No início dos anos 1960, enquanto o Brasil já apresentava moderno e integrado parque industrial, em razão da implementação do Plano de Metas do governo JK, e mercado nacional quase que totalmente formado, o Paraná se caracterizava por relações econômicas extremamente frágeis entre o norte cafeeiro e o restante do Estado.

A expansão do norte, ligada à economia paulista, não cria condições para sustentar forte crescimento e diversificação em razão de sua base produtiva caracterizar-se pela transferência de produção agrícola para São Paulo e pela aquisição de produtos manufaturados daquele Estado. Por outro lado, as regiões paranaenses de povoamento mais antigo apresentavam agricultura pouco dinâmica e com baixo grau de integração ao mercado.

Desse modo, a concorrência paulista, a existência de áreas pouco dinâmicas e economicamente desintegradas, a ausência de um sistema público adequado de financiamento dos investimentos industriais e as precárias condições de infra-estrutura de transporte e de geração de energia elétrica estão na raiz da frágil base econômica do Paraná no começo dos anos 1960, que se apoiava numa indústria ligada à produção primária e de baixo grau de elaboração, notadamente beneficiamento de café e madeira.

Buscando superar essa debilidade, foi criada a Companhia de Desenvolvimento do Paraná (Codepar) em 1962, objetivando atender às exigências de financiamento da infra-estrutura básica do Estado, condição essencial para dinamizar o escoamento da produção agrícola e receber, posteriormente, a indústria. A propósito, a Codepar (transformada em Banco de Desenvolvimento do Paraná, em 1968) e o Fundo de Desenvolvimento Econômico (FDE) ensejaram a primeira tentativa de industrialização regional, assentada nos pressupostos cepalinos de substituição de importações, implícitos nas recomendações contidas no Plano de Desenvolvimento do Estado do Paraná (Pladep), elaborado no final dos anos 1950.

Os anos 1970 foram palco de profunda diversificação e grande dinamismo do aparelho produtivo estadual. Além do salto infra-estrutural da década de 1960, resultado da realização de grandes obras voltadas ao aumento da oferta de energia elétrica, à construção de rodovias e ferrovias, à adequação do porto de Paranaguá, à implantação de rede de armazenagem pública, à modernização das telecomunicações etc., outros fatores contribuíram para esse surto econômico, como a elevação da taxa de investimento da economia nacional, a grande capacidade de resposta da agricultura aos estímulos modernizantes da política de crédito agrícola pós-1966 e, notadamente, o programa de atração de indústrias realizado pelo governo estadual entre 1975 e 1978. 
Como conseqüêencia, o Paraná presenciou a instalação de segmentos modernos, como os complexos cimenteiro, metal-mecânico e de refino de petróleo na Região Metropolitana de Curitiba (RMC), a modernização dos ramos tradicionais da madeira, papel e celulose, a diversificação do agronegócio (soja, café, laticínios, rações, frigoríficos etc.), além da desconcentração geográfica dos gêneros da madeira, papel e das atividades agroindustriais.

Nos anos 1980, a estagnação econômica nacional, resultante da falência do Estado, do desequilíbrio das contas externas, da suspensão dos fluxos financeiros internacionais pós-crise mexicana, da indefinição de esquemas viáveis de financiamento dos investimentos de longo prazo, do reduzido volume de inversóes fixas, do crescente atraso científico e tecnológico e da queda do poder aquisitivo dos salários, devido à aceleração da inflação, contribuiu para o moderado dinamismo da base econômica regional. A par disso, houve a continuidade da modernização agroindustrial (fiação de algodão, Proálcool, subprodutos do milho, industrialização de aves e maltaria), a plena maturação de grandes investimentos efetuados em segmentos modernos e/ou novos da indústria estadual em fins dos anos 1970 e início dos 1980 (fertilizantes nitrogenados, ônibus e caminhões, papel de imprensa, cigarros, micro e minicomputadores) e, acionadas pelo Plano Cruzado em 1986, algumas inversões nos ramos de siderurgia e refrigeradores e freezers.

Até essa data, o carro chefe da expansão econômica no Paraná continuou sendo as atividades direta ou indiretamente articuladas com o setor rural, refletindo o grau intermediário de industrialização das matérias-primas agrícolas e reduzida capacidade de geração de renda e de arrecadação de impostos, em razão da grande interferência de fatores fortuitos e choque exógenos, como clima, injunções de política agrícola federal e flutuações dos mercados externos.

Nos anos 1990, embora a economia paranaense ainda revelasse comportamento oscilante, atribuído à contração econômica do final do governo Sarney e aprofundada durante a gestão Collor, à instabilidade das cotaçôes internacionais dos produtos primários, ao dumping internacional e à precária política agrícola praticada pelo governo federal, alguns fatores estruturais, embora incipientes, criavam as condições para a rápida alteração do perfil tecnológico da base produtiva estadual, num cenário de crescimento auto-sustentável da economia nacional. Dentre os elementos de reestruturação se destacaram a reprodução mais intensa dos ajustes técnico-produtivo-gerenciais comandados pela iniciativa privada do País na direção da melhoria dos padrões de eficiência produtiva, os primeiros resultados da integração do Brasil com os países do Mercosul e algumas ações das administrações estaduais relativas à ampliação e restauração e/ou aprimoramento da infra-estrutura, tais como: reparação/conservação de rodovias estaduais, conclusão de obras da usina hidroelétrica de Salto Segredo, 
duplicação da BR 376 no trecho Curitiba, no Paraná, a Joinville, em Santa Catarina, reativação das obras de construção da ponte sobre o rio Paraná, em Guaíra, término do primeiro trecho da ferrovia Ferroeste, entre Guarapuava e Cascavel etc.

Conjugado a isso, a estabilização monetária e a liberalização comercial, a partir de 1994, criaram condições para o alargamento do horizonte temporal de previsibilidade dos agentes, a redescoberta do Brasil pelos investidores, a recuperação do poder de compra da população e a ampliação das relações externas, especialmente com a consolidação do Mercosul. O Plano Real também abriu espaço para a restauração do movimento de desconcentração industrial do eixo Rio-São Paulo-Minas em direção às cidades de portes médio e grande do Centro Sul do País, próximas a São Paulo e ao Mercosul, dotadas de infra-estrutura, menor custo de mão-de-obra e reduzida organização e atuação sindical.

Nesse particular, o Paraná revelou enorme capacidade de atendimento a esses condicionantes, especialmente em virtude de sua posição geográfica e de sua rede de infra-estrutura, vantagens estas que foram multiplicadas pela reativação de aparato institucional composto pelo Programa Paraná Mais Emprego, criado em 1992 com a denominação de Bom Emprego Fiscal (variante aprimorada do antigo Programa Especial de Fomento à Industrialização - PEFI, criado em 1981, e Programa de Estímulo às Atividades Produtivas - PEAP, instituído em 1986), e pelos já citados FDE e Codepar.

O Paraná Mais Emprego oferece à empresa incentivada a prorrogação de prazo de recolhimento do ICMS por 48 meses e o pagamento parcelado em outros 48 meses, com correção monetária e sem juros. Na prática, o incentivo funciona como uma espécie de financiamento para capital de giro, lastreado nos recursos provenientes das atividades correntes realizadas pelas próprias empresas beneficiárias. Se a empresa incentivada efetuar novos investimentos, poderá pleitear novo enquadramento no programa. As unidades do ramo mecânica, material elétrico e de comunicação, material de transporte e química podem dispor de prazo de carência complementar de 12 a 24 meses se, no encerramento do incentivo inicial, tiverem registrado compras de $40 \%$ e 60\%, respectivamente, de empresas sediadas no próprio Estado.

Os resultados dessa estratégia já começaram a aparecer, apesar da conjuntura de crise vivida pelo País, principalmente desde setembro de 1998, com a crise russa, do choque de juros e do pacote fiscal desse ano e das mudanças no câmbio no início de 1999. Tanto é assim que, ainda de acordo com Lourenço (2000), o Paraná acumulou estoque de investimentos de quase US\$ 29 bilhões, em projetos industriais privados e obras de infra-estrutura, programados ou realizados entre 1995 e 1999 com maturação prevista até 2003, o que corresponde à segunda maior carteira do País, depois de 
São Paulo, representando quase $8 \%$ do total confirmado para o Brasil nesse período, contra aproximadamente $20 \%$ de São Paulo, $5,5 \%$ do Rio Grande do Sul e $2 \%$ de Santa Catarina.

A guinada da economia paranaense está estruturada em vultosos planos de inversão centrados em cinco vetores estreitamente articulados, segundo Lourenço (2000). O primeiro é o relativo à formação do pólo automotivo, iniciado na década de 1970, com a vinda da New Holland, fabricante de colheitadeiras e de tratores agrícolas, e da Volvo (ônibus e caminhões). Mais recentemente, o pólo incorporou as montadoras Renault, Volks/Audi, Chrysler e aproximadamente 60 fornecedores diretos globais, especialmente a Tritec motores, a Detroit Diesel, a Renault motores, a Dana Corporation, a Lear Corporation, a Siemens e a Bertrand Faure, além da Companhia Siderúrgica Nacional.

O novo parque paranaense reproduz os rearranjos tecnológicos encontrados na indústria automobilística mundial, cujos elementos principais são a desverticalização, a terceirização de serviços e, notadamente, a adoção do sistema just in time, baseado na integração dos supridores de primeira camada com as montadoras via consórcio modulares.

O segundo vetor de expansão engloba a verticalização das cadeias agrícolas e agroindustriais liderada pelas cooperativas que dominam a oferta de matéria-prima no Estado - absorvendo cerca de $55 \%$ da produção agropecuária - detêm expressiva parcela da capacidade de industrialização, possuem estruturas gerenciais e de capacitação avançadas, semelhantes às das grandes empresas privadas, e atuam de forma regionalizada, facilitando não só a identificação de oportunidades como também a alocação de recursos em verticalização e integração de forma mais eficiente, nas regiôes produtoras.

O terceiro bloco compreende a expansão da capacidade produtiva do complexo madeireiro-papeleiro, aproveitando a disponibilidade de matéria-prima proveniente de reflorestamentos e a melhoria de competitividade proporcionada pela alteração cambial, incorporando tanto a modernização dos segmentos tradicionais quanto a diversificação da carteira de produtos, principalmente depois de grandes inversões realizadas nas áreas de tecnologia de ponta, como Medium Density Fiberboard (MDF) e Oriented Standard Board (OSB), atreladas à demanda da indústria moveleira e da construção civil.

O quarto eixo envolve o rearranjo no front externo, especialmente com os mercados do Cone Sul, que representam importante fronteira para o crescimento dos fluxos comerciais, notadamente para as pequenas e médias empresas. Nesse particular, as 
vendas externas paranaenses para o resto do mundo elevaram de US\$ 1,87 bilhão em 1990 para US\$ 4,23 bilhões em 1998, com a participação do Estado no total exportado pelo País passando de 5,9\% para 8,3\%, atingindo o quarto lugar no ranking nacional.

A participação do Paraná nas exportações para o Mercosul passou de 4,1\% em 1990 para 11,7\% em 1998, o que levou o bloco a se constituir no terceiro parceiro comercial do Estado, atrás da União Européia $(38,4 \%)$ e da Ásia $(16,8 \%)$.

Finalmente, o quinto vetor está relacionado ao melhor aproveitamento das vocaçóes e ao desenvolvimento das aptidóes regionais, nas suas diferentes escalas, envolvendo novos atores locais ativos. Esse eixo deve ser reforçado pela identificação de oportunidades ligadas às áreas do conhecimento e da informação, por meio da criação de pólos tecnológicos, incubadoras e infovias (redes de fibras ópticas), apoiados nas ações das unidades descentralizadas do Centro Federal de Educação Tecnológica (CEFET), das universidades e faculdades estaduais e em outros projetos públicos e privados.

Além do que foi concluído até agora, o que pode ser acrescentado a partir das informações da Tabela 1 é que o setor Cooperativa (l) reforça sua importância na economia estadual ao ser considerado setor-chave, no conceito restrito, em 1980 e 1985. Nos anos de 1990 e 1995, o setor Cooperativa continua chave, admitindo o relaxamento desse conceito. É certo que a perda de importância, principalmente dos setores alimentares mais tradicionais, contribuiu para isso.

De fato, a indústria alimentar paranaense perdeu posição em termos de valor agregado e valor da produção gerados na economia do Estado ao longo do período, apesar do menor decréscimo ou mesmo do crescimento dos setores alimentares mais modernos. (Rodrigues, 2000). Também os índices de ligações de Rasmussen-Hirschman foram, de forma geral, decrescentes para a indústria alimentar estadual no correr dos anos (Tabela 1).

Algumas razões específicas poderiam ser arroladas para o menor dinamismo da indústria alimentar e, conseqüentemente, do setor Cooperativa nos anos 1990. Dentre elas estariam, provavelmente, a redução e posterior eliminação do subsídio ao crédito rural ocorrida na década de 1980, conduzindo, mais recentemente, à redefinição e maior racionalização dos planos de investimento das cooperativas, a maior concorrência com os produtos alimentares dos parceiros brasileiros no Mercosul, notadamente a Argentina, a partir da abertura comercial e a tendência de maior diversificação do parque industrial do Estado. 


\subsubsection{As Relações Cumulativas na Economia Paranaense}

As ligações cumulativas setoriais na economia do Paraná estão representadas nas Figuras 1 a 4, em que o resultado empírico engloba 33 setores representados por bolhas, cujas superfícies são proporcionais ao valor adicionado do setor em questão. O tamanho das bolhas indica a dimensão do possível impulso que pode ser emitido de cada setor para a economia estadual.

Para efeito de comparação, foram plotados nas Figuras os valores médios das ligações cumulativas para trás e para frente da economia do Estado. Para 1980, 1985 e 1990, essas médias foram iguais a 0,7 e para 1995, 0,6.

De acordo com essas medidas, os setores Celulose, Papel e Gráfica (10) e Indústria Têxtil (15) mostraram, nos anos estudados, as mais favoráveis combinaçôes das ligações para frente e para trás, todas acima das respectivas médias das ligações do Paraná. Esses dois setores foram considerados chave no conceito restrito do índice de Rasmussen-Hirschman. Cabe ressaltar o setor Fabricação de Minerais não Metálicos (4), que apresentou ligações cumulativas acima da média para três dos quatro anos estudados.

Outros três setores estiveram nessa posição em anos diferentes, a saber: Fabricação de Outros Produtos Alimentares não-Cooperativa (23), em 1980, Indústria de Artigos de Plástico (14), em 1980 e 1985, e Material de Transporte (8), em 1990, indicando que as ligações desses setores com os demais setores da economia paranaense tiveram comportamento errático.

Nos anos em tela, o setor Química (12) destacou-se com as maiores ligações cumulativas para frente, enquanto dois setores alimentares, quais sejam, Indústria do Café nãoCooperativa (17), em 1980 e 1985, e Fabricação de Óleos Vegetais não-Cooperativa (22), em 1990 e 1995, despontaram com as maiores ligações cumulativas para trás. Cabe notar, entretanto, que o comportamento das ligaçóes nesses dois últimos casos foi bastante diferente. Enquanto o setor (17) teve suas ligações cumulativas para trás e para frente fortemente decrescentes, o setor (22) apresentou ligeiro decréscimo das ligações para trás e aumento das ligações para frente, revelando maior importância para a economia do Estado nos anos mais recentes.

Isso ocorreu em razão da própria mudança na composição da produção agrícola da economia paranaense no período. Assim, apesar de o café ter sido, durante muito tempo, o principal produto da economia estadual, respondendo por $62,8 \%$ da produção brasileira na safra 1962/63 (Padis, 1981), as fortes geadas e o processo de substituição de culturas, ambos ocorridos a partir dos anos 1970, reduziram sua participação e 
impulsionaram a cultura da soja, que se transformou, então, no produto mais importante da agricultura estadual.

O setor Cooperativa (1), objeto de maior atenção do estudo, o setor Agropecuária não-Cooperativa (2) e os setores do ramo serviços, notadamente Serviços Industriais de Utilidade Pública (25), Construção Civil (26), Comércio (27), Instituições Financeiras (30), Administração Pública (32) e Outros serviços (33), se destacaram pela emissão de impulsos econômicos nos anos analisados.

A análise das Figuras 1 a 4 permite inferir que os setores com maior participação relativa na economia estadual (tamanho das bolhas) não foram os que apresentaram as maiores ligações cumulativas no período. Isto significa dizer que embora alguns setores tenham crescido na economia paranaense, resultando em maior impacto econômico potencial, seus índices de ligações cumulativas não se revelaram os maiores. Reside aqui uma das contribuições de Oosterhaven et al. (1999a e 1999b), qual seja, a de mostrar que o tamanho das ligações não informa sobre a proporção dos impulsos transmitidos pelos setores.

De fato, no caso da economia paranaense, os setores do ramo serviços foram os que mais aumentaram suas participações no valor adicionado total no período em tela. Esses setores, embora apresentassem valor adicionado elevado, são setores que se orientaram, primariamente, para o consumidor final e não para venda a outras indústrias, característica que pode diluir as ligações entre setores.

\section{FIGURA I-LIGAÇÕES CUMULATIVAS, PARANÁ, 1980}

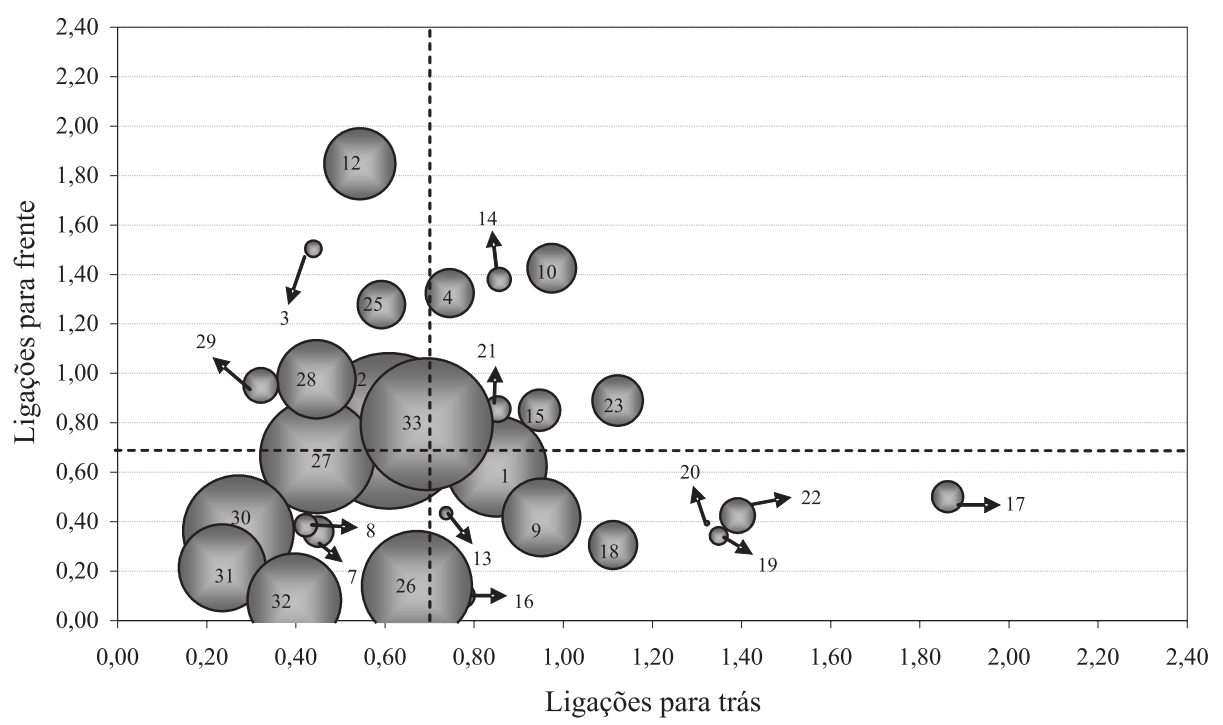

Fonte: elaboração dos autores. 
FIGURA 2 - LIGAÇÕES CUMULATIVAS, PARANÁ, 1985

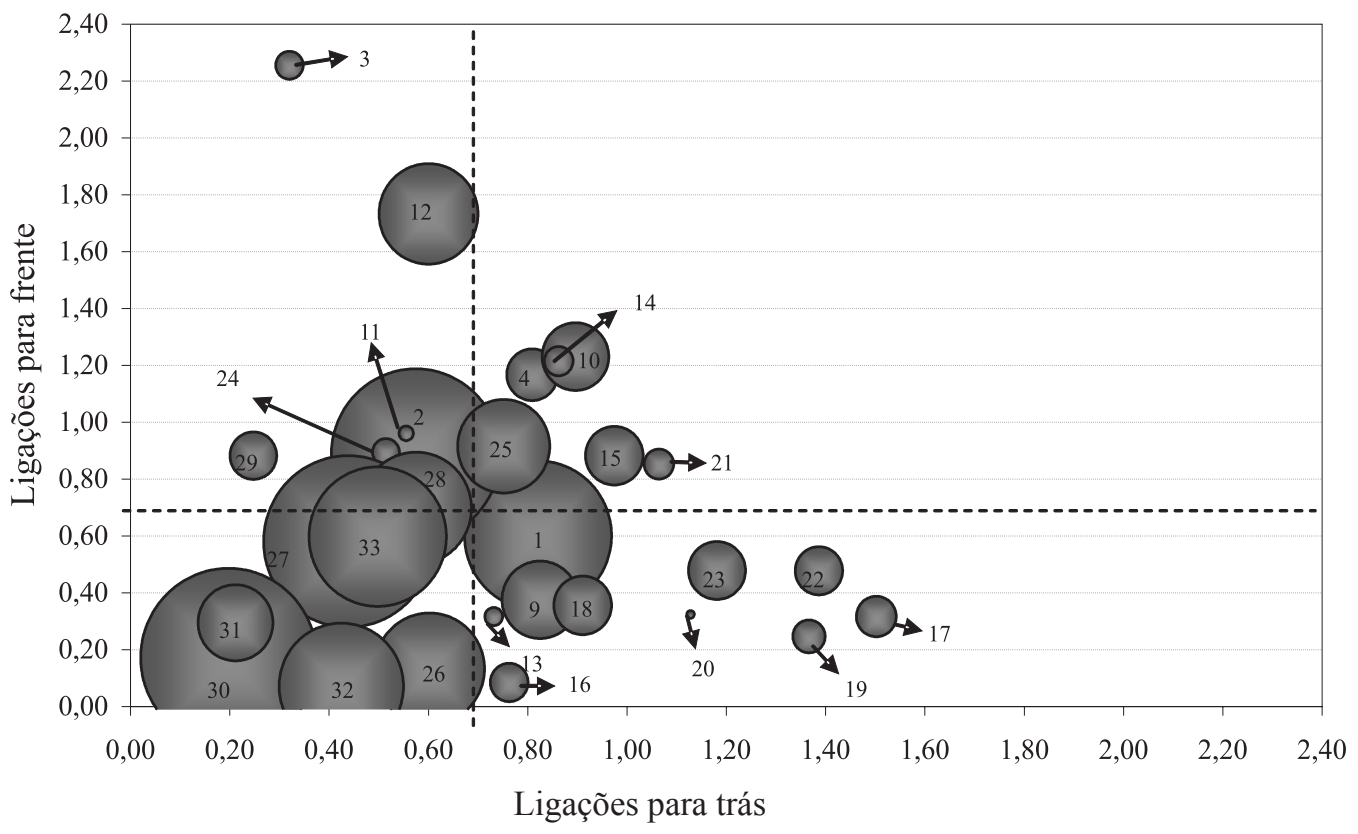

Fonte: elaboração dos autores.

FIGURA 3 - LIGAÇÕES CUMULATIVAS, PARANÁ, 1990

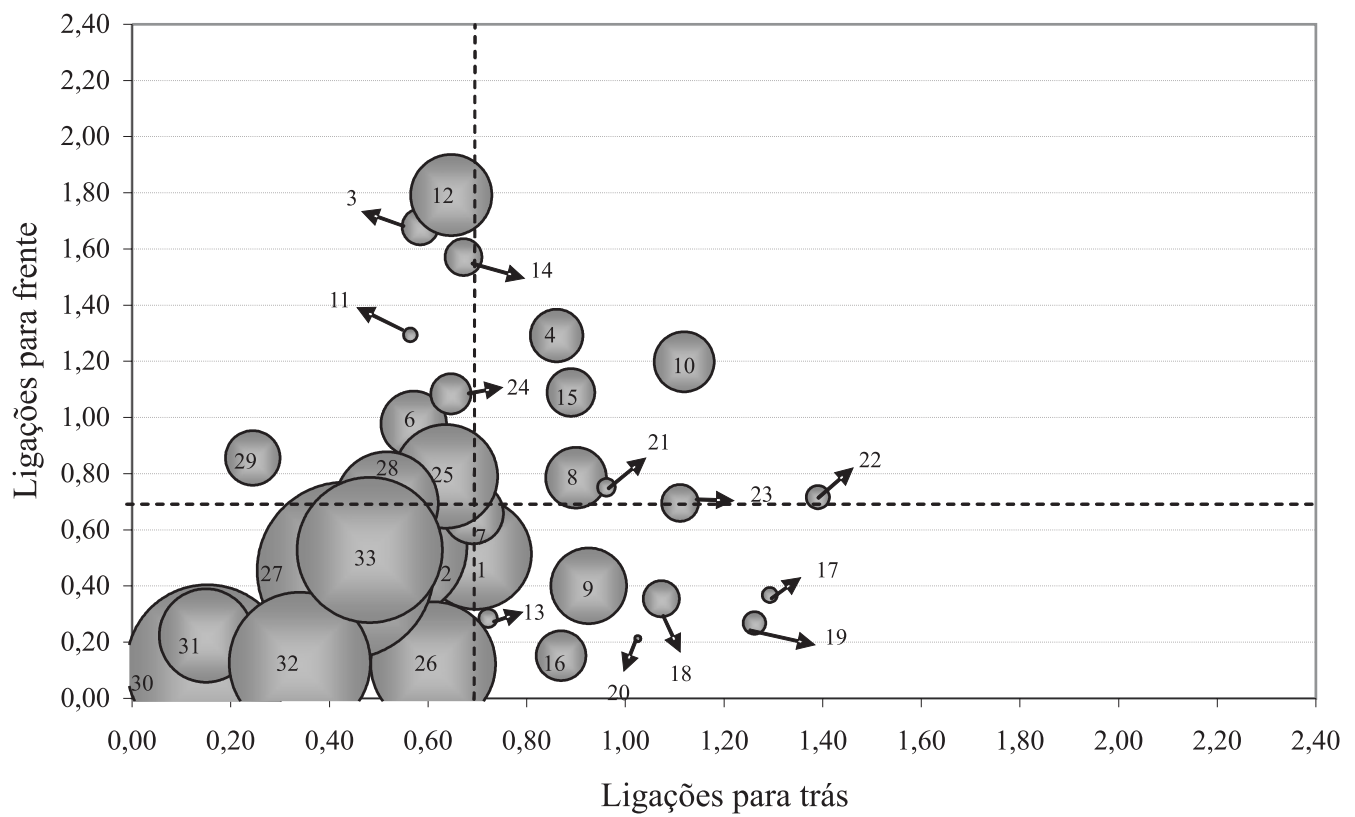

Fonte: elaboração dos autores. 


\section{FIGURA 4 - LIGAÇÕES CUMULATIVAS, PARANÁ, 1995}

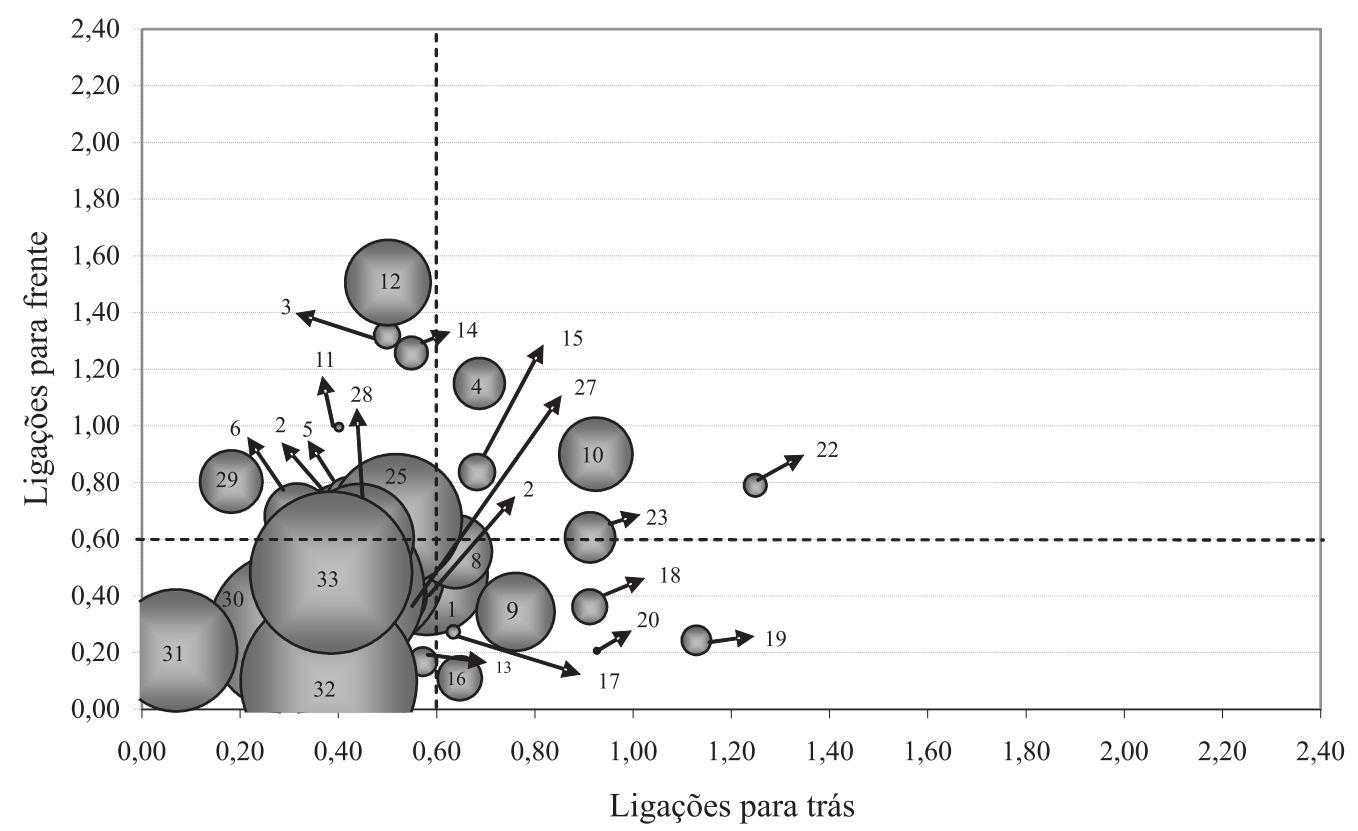

Fonte: elaboração dos autores.

Quanto ao setor Cooperativa, a integração existente entre a agricultura e a agroindústria pode ser apontada como a responsável pelos baixos índices de ligações com os outros setores. É como se o setor Cooperativa passasse a ter a capacidade de se auto-abastecer dos produtos agropecuários utilizados como matéria-prima nas suas indústrias. A lógica de funcionamento das cooperativas esclarece este fato. Os agricultores associados às cooperativas são, ao mesmo tempo, seus donos e usuários. Embora não sejam estabelecidas regras contratuais entre cooperado e cooperativa no sentido de produção e comercialização, inexistindo, desse modo, obrigatoriedade de entrega da produção à cooperativa e de participação em transações preferenciais com essa empresa, o cooperado, por princípio, deposita ou deveria depositar na cooperativa o resultado da sua produção agropecuária. Isto reduziria a dependência da indústria cooperativa no que se refere à oferta externa desses produtos.

Finalmente, uma tendência geral observada na economia paranaense foi a de decréscimo tanto das ligações cumulativas setoriais para frente quanto para trás, o que veio, inclusive, refletir na queda da média destas ligaçóes de 0,7 em 1980, 1985 e 1990 para 0,6 em 1995. Uma possível causa para esse comportamento é o crescimento das ligações cumulativas dos setores da economia paranaense com setores externos à economia estadual, ou seja, o crescimento dos requerimentos de importaçóes e a elevação das exportações ao longo do período 1980-95. Isto é plausível em razão: a) do crescimento da economia estadual no período; b) do processo de abertura econômica 
em curso no Brasil, viabilizado notadamente, a partir dos anos 1990, com o Mercosul e c) da posição estratégica que o Paraná ocupa neste cenário.

\subsubsection{Estrutura de Produção Paranaense: A 'Topografia' Econômica}

A estrutura produtiva da economia do Paraná para os quatro anos estudados está retratada nas Figuras 5 a 8. Nelas, pode-se visualizar a 'topografia' setorial da economia do Estado, tomando as medidas de intensidade de 1980 como base.

Observou-se que, no ano de 1980, o pico da hierarquia ocorreu na interseção do setor Química (12) e Indústria do Café não-Cooperativa (17), seguido pelo setor Química (12) e Fabricação de Óleos Vegetais não-Cooperativa (22). Os setores Química (12) e Agropecuária não-Cooperativa (2), seguidos do setor Outros Serviços (33) são, visivelmente, os que apresentaram, com a Indústria do Café não-Cooperativa (17), as combinações com maiores picos em 1980. A partir do quarto cruzamento, os picos decresceram de forma mais homogênea (Figura 5 ).

No cenário de 1985, embora o pico da hierarquia seja mantido com os mesmos setores, é interessante salientar dois pontos que o diferencia do de 1980: a) o pico da hierarquia em 1985 ocorreu com valores menores do que em 1980; b) do quarto cruzamento em diante, emergiram setores $(27,28,10,15,25)$ que apresentaram crescimento das ligações para frente e para trás em 1985, relativamente a 1980 (Figura 6).

O ano de 1990 mostra paisagem setorial 'menos comportada' da economia estadual, ou seja, com maior número de setores despontando no cenário econômico. Em outras palavras, houve, nesse ano, melhor distribuição das ligações para frente e para trás, além de novo decréscimo nos valores dos picos. Estes passaram a se localizar, respectivamente, nas interseções dos setores Química (12) e Fabricação de Óleos Vegetais não-Cooperativa (22), acompanhado do setor (12) e Indústria do Café nãoCooperativa (17) (Figura 7). Este comportamento reforça o processo de substituição do café pela soja ocorrido na economia paranaense, conforme salientado anteriormente. Em 1995, o 'retrato' da estrutura econômica paranaense manteve os picos da hierarquia iguais aos de 1990 (Figura 7 e 8). 
FIGURA 5 - TOPOGRAFIA DA ESTRUTURA ECONÔMICA DO PARANÁ, 1980

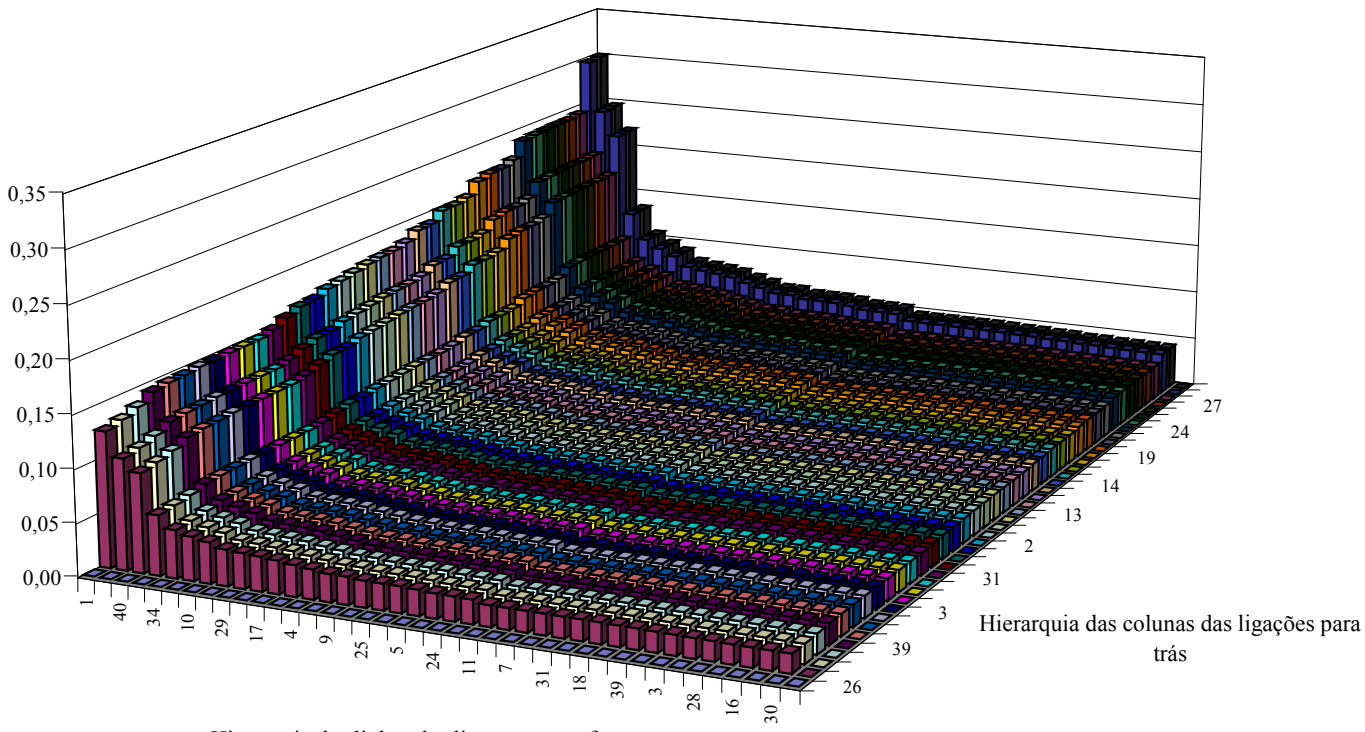

Hierarquia das linhas das ligações para frente

Fonte: elaboração dos autores.

\section{FIGURA 6 - TOPOGRAFIA DA ESTRUTURA ECONÔMICA DE 1985 USANDO A HIERARQUIA DO PARANÁ DE 1980}

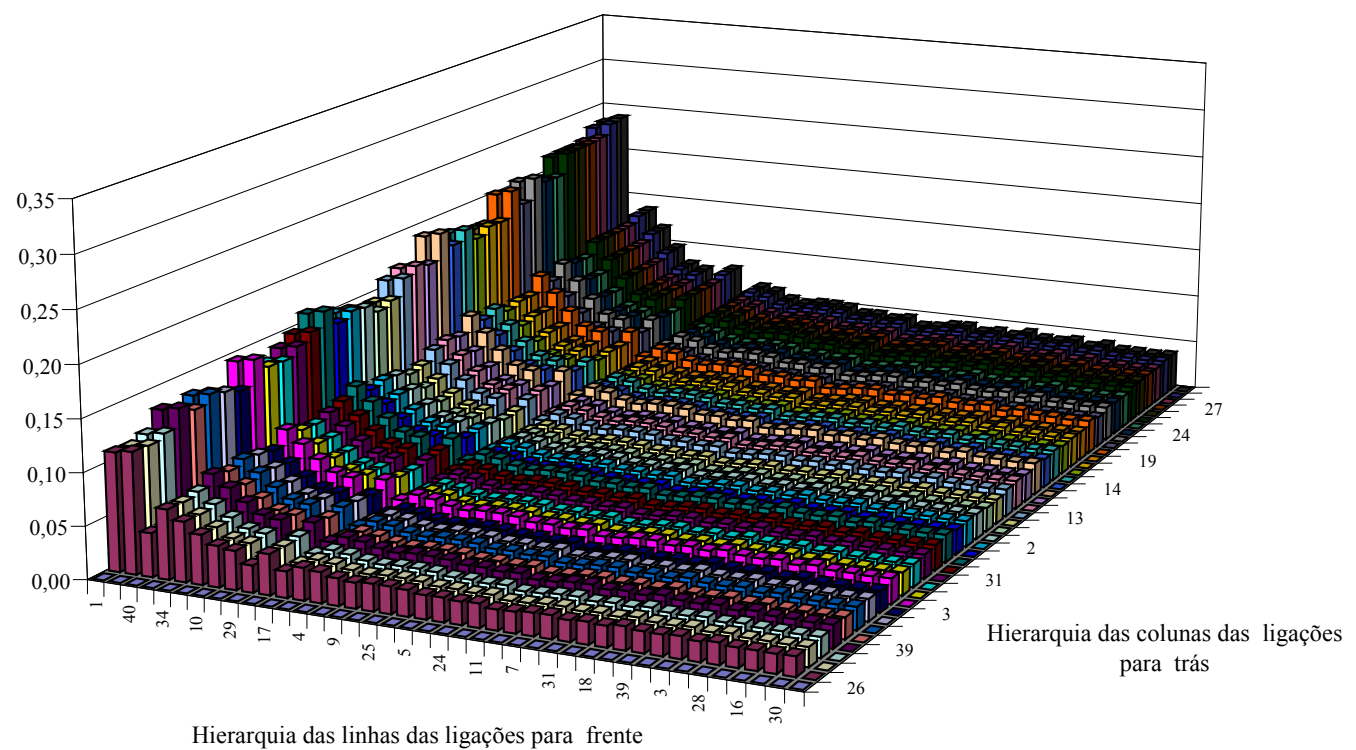

Fonte: elaboração dos autores. 
FIGURA 7 - TOPOGRAFIA DA ESTRUTURA ECONOAMICA DE 1990 USANDO A HIER ARQUIA DO PAR ANÁ DE 1980

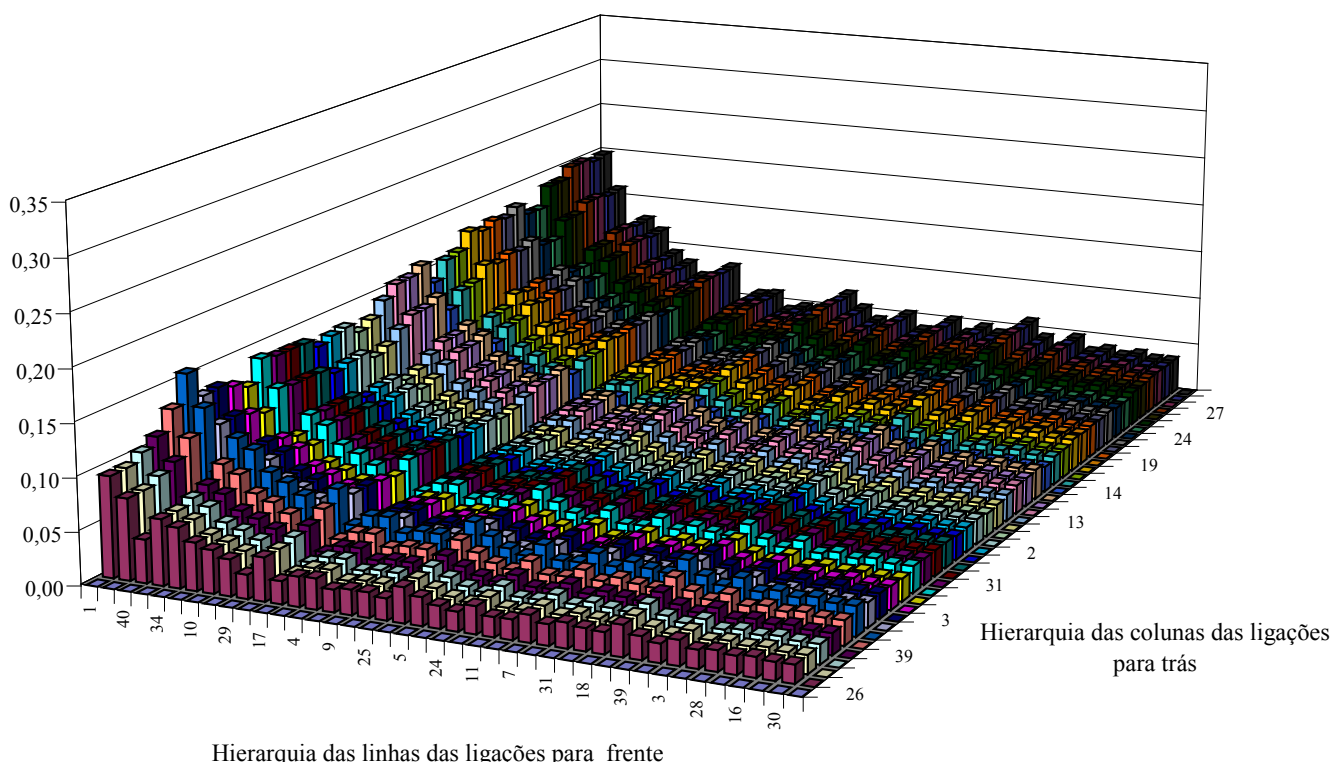

Fonte: elaboração dos autores.

\section{FIGURA 8 - TOPOGRAFIA DA ESTRUTURA ECONÔMICA DE 1995 USANDO A HIER ARQUIA DO PARANÁ DE 1980}

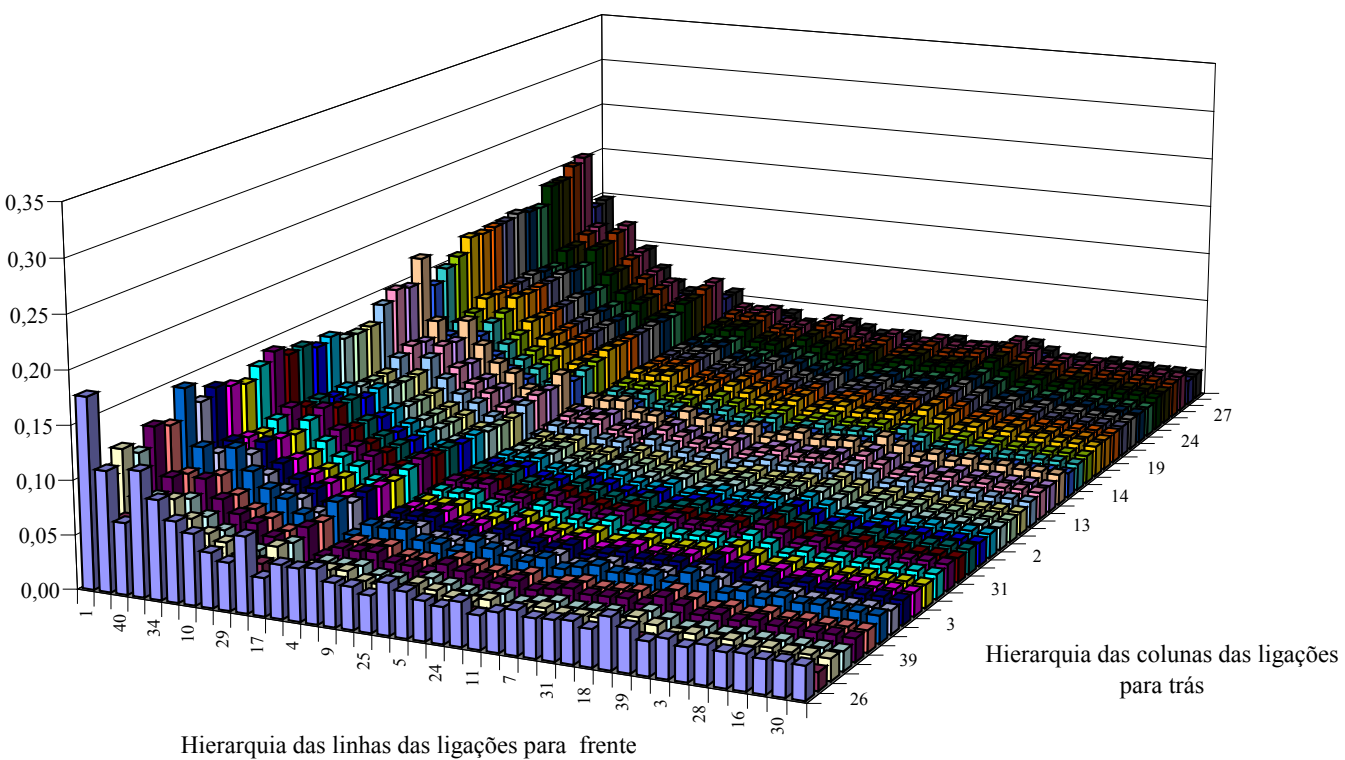

Fonte: elaboração dos autores. 
Comparando as Figuras 5 a 8 pode-se perceber que de 1980 para 1995 a estrutura setorial da economia paranaense mostrou, além de redução nos valores dos picos, conformação menos desigual entre eles, revelando maior diversificação da estrutura produtiva, crescimento das relações externas e, conseqüentemente, incremento da complexidade econômica.

\subsubsection{Técnicas de Análise Regional}

As técnicas usadas neste estudo para descrever e analisar a estrutura produtiva regional permitiram verificar, conjuntamente, a evolução do comportamento e do tamanho dos encadeamentos entre os setores da economia paranaense e a conformação da estrutura produtiva estadual no período 1985-1995.

Os índices de Rasmussen-Hirschman e as relações cumulativas indicaram os setores que apresentaram mais oportunidades em termos de estímulos para novos suprimentos de matérias-primas e para provisão de insumos a outros setores, além de mostrar, no caso das relações cumulativas, a dimensão dos impulsos transmitidos por eles. Por sua vez, a matriz intensidade mostrou a ordenação dos setores ao longo dos anos estudados, revelando, em uma 'fotografia', as mudanças na estrutura produtiva estadual.

Não obstante, é importante salientar a dificuldade que existe para se classificar setores-chave, uma vez que estes podem ser considerados como tal em razão dos objetivos da industrialização ou da escolha do pesquisador no que se refere à técnica de seleção adotada. Em outras palavras, não deve ser esquecido que toda classificação é arbitrária, pois um setor pode se apresentar como chave, em dada economia, por ser importante gerador de renda, ou por apresentar fortes impactos diretos e indiretos sobre a produção, ou por ser um importante criador de emprego, ou por possibilitar maior pagamento de impostos etc.

Assim, em que pesem as limitações destas técnicas e, conseqüentemente, a necessidade de conjugá-las com outros métodos de análise regional, acreditamos que foi possível apontar as cooperativas agropecuárias, notadamente as dedicadas aos setores alimentares mais modernos, como Abate de Animais, Indústria de Laticínios, Fabricação de Outros Produtos Alimentares e Fabricação de Óleos Vegetais, outros setores da indústria de transformação, tais como Máquinas e Equipamentos, Material de Transporte, Metalurgia e Material Elétrico/Eletrônico, e os setores do ramo serviços como merecedores de atenção por parte de políticas e investimentos públicos e privados que têm como objetivo o crescimento e o desenvolvimento da economia estadual. 


\section{CONSIDERAÇÕES FINAIS}

A realização desta pesquisa permitiu constatar que as cooperativas constituem setorchave e, portanto, setor dinâmico na economia do Paraná. Essas empresas são, enquanto atuantes no setor Agropecuária e na Indústria Alimentar, grandes emissoras de impulsos econômicos.

Outra constatação importante refere-se ao fato de as cooperativas agropecuárias apresentarem, para todos os anos estudados, coeficientes técnicos de produção bastante similares aos das empresas não-cooperativas que atuam na agropecuária e na indústria alimentar. Considerando que esses coeficientes refletem a base tecnológica de produção em dado ano, conclui-se que as cooperativas estão acompanhando de perto a evolução tecnológica ocorrida nesses setores. Inseridas numa realidade cada vez mais competitiva, essas empresas têm consciência da necessidade de investir em máquinas e equipamentos, na criação de novos produtos e processos, na gestão, no controle de qualidade, na inovação tecnológica e em recursos humanos para que possam concorrer num mercado cada vez mais globalizado.

A tendência de redução das ligações setoriais no Estado e de diversificação da estrutura produtiva da economia paranaense ao longo do período estudado foi outra conclusão a que se chegou. Considerando o cenário de crescimento da economia estadual, conjugado com o processo de abertura da economia e de integração com os parceiros do Mercosul, em que o Paraná ocupa posição estratégica, uma explicação provável é que esteja ocorrendo o crescimento das ligaçôes dos setores da economia paranaense com setores externos à economia estadual.

Como sugestóes para trabalhos futuros que possam complementar e/ou aprofundar a presente pesquisa destaca-se a necessidade de: a) desagregar outros setores nos quais as cooperativas agropecuárias atuam, a saber, Química (destilarias de álcool de cana-de-açúcar), Têxtil (fios de algodão e seda), Comércio, Transporte, Instituições Financeiras e Outros Serviços, de forma a quantificar mais precisamente a participação destas empresas na economia Estadual; b) estudar, de forma explícita, o impacto da abertura econômica sobre as relações intersetoriais no Estado e; c ) estender o estudo para as cooperativas agropecuárias nacionais.

\section{REFEREANCLAS BIBLIOGRÁFICAS}

Guilhoto, J. J. M; Sonis, M.; Hewings, G. J. D; Martins, E. B. Índices de ligações e setores-chave na economia brasileira: 1959/80. Pesquisa e Planejamento Econômico, v. 24 , n. 2 , p. $287-314,1994$. 
Hewings, G. J. D. The empirical identification of key sectors in an economy: a regional perspective. The Developing Economies, v. 20, p. 173-195, 1982.

Hirschman, A. O. The strategy of economic development. New Haven: Yale University Press, 1958. 217p.

Lourenço, G. M. A economia paranaense nos anos 90: um modelo de interpretação. Curitiba: Editora do Autor, 2000. 90p.

McGilvray, J. W. Linkages, key sector and development strategy. In: Leontief, W. (Ed.), Structure, system and economic policy. Cambridge: Cambridge University Press, Cap. 4, p. 49-56, 1977.

Myrdal, G. Solidaridad o desintegración. México, DF, Buenos Aires: Fondo de Cultura Económica, 1957.

Organização das Cooperativas Brasileiras (OCB). Números do cooperativismo brasileiro. Brasília: Departamento Técnico e Econômico/Banco de Dados, 1997. 20 p.

Organização e Sindicato das Cooperativas do Paraná (OCEPAR). O cooperativismo paranaense. Curitiba - PR, 1997. 14 p. (Coleção História do Cooperativismo).

Oosterhaven, J.; Eding, G. J.; Stelder, D. Clusters, forward and backward linkages, and bi-regional spillovers: policy implications for the two Dutch mainport regions and the rural north. 39 European Congress of the Regional Science Association International, University College Dublin, August 23-27, 1999a. 13p.

. A new generation of Dutch bi-regional input-output tables: construction and a new cluster analysis application. International Input-Output Seminar, Guadalajara, Mexico, September 2-4, 1999b. 21p.

Padis, P. C. Formação de uma economia periférica: o caso do Paraná. São Paulo: Hucitec; Curitiba: Secretaria da Cultura e Esporte do Governo do Paraná, 1981. 235p.

Perroux, F. Conceito de pólos de crescimento. In: Schwartzman, J. (Ed.), Economia regional: textos escolhidos. Belo Horizonte: CEDEPLAR, 1977, p. 145-156.

Rasmussen, P. N. Studies in intersectoral relations. Amsterdam: North-Holland, 1956.

Rodrigues, R. L. Cooperativas agropecuárias e relações intersetoriais na economia paranaense: uma análise de insumo-produto. 2000. 175p. Tese (Doutorado) - Escola Superior de Agricultura "Luiz de Queiroz", Universidade de São Paulo. Piracicaba.

Sonis, M.; Hewings, G. J. D; Guo, J. Input-output multiplier product matrix. Urbana: University of Illinois. Regional Economics Applications Laboratory, 1997. (Discussion Paper 94-T-12).

Sonis, M.; Hewings, G. J. D. Economic landscapes: multiplier product matrix analysis for multiregional input-output systems. Hitotsubashi Journal of Economics, v. 40, n. 1, p. 59-74, June 1999. 